DOI 10.37882/2223-2982.2022.01.06

\title{
ТОРГОВОЕ ОБСЛУЖИВАНИЕ ЖИТЕЛЕЙ АЛТАЙСКОГО КРАЯ В КОНТЕКСТЕ ЭКОНОМИЧЕСКИХ ПРЕОБРАЗОВАНИЙ ВТОРОЙ ПОЛОВИНЫ 1960-Х - НАЧАЛА 1990-Х ГГ.1
}

\section{TRADE SERVICES FOR RESIDENTS IN THE ALTAI KRAI IN THE CONTEXT OF ECONOMIC REFORMATIONS AT THE SECOND HALF OF THE 1960S - EARLY $1990 S$}

\section{E. Demchik \\ G. Gryanikova}

Summary: The article analyzes the socio-economic consequences of the 1965 reforms and the reforms of "perestroika» period, aimed at updating the economic ties between the state and enterprises with a view to the formation of market relations. Based on the materials of the State Archive of the Altai Krai, official statistics and the regional press, general trends in the production of consumer goods were identified, the state of trade and consumer services of the population was considered, and the level of development of public catering was described. The focus of state policy on the development of trade and household services, food and light industries is noted. The partial implementation of new measures has formed a contradictory situation in satisfaction of population requirements while there was the stable production growth in the region enterprises. Conclusions were drawn on the need for an integrated approach to innovations considering the previous state of the economy and regional characteristics.

Keywords: trade services, economic reforms, perestroika, the market, the history of everyday life, Altai Krai.

\author{
Демчик Евгения Валентиновна \\ Д.и.н., профессор, Алтайский государственный \\ университет (Барнаул) \\ demtchikev@mail.ru \\ Гряникова Галина Андреевна \\ ассистент, Алтайский государственный университет \\ (Барнаул) \\ galya9309@mail.ru
}

Аннотация: B статье анализируются социально-экономические последствия реформ 1965 г. и периода «перестройки», направленных на обновление экономических связей государства и предприятий с перспективой становления рыночных отношений. На основе материалов Государственного архива Алтайского края, данных официальной статистики и региональной прессы выявлены общие тенденции производства товаров широкого потребления, рассмотрено состояние торгового и бытового обслуживания населения, охарактеризован уровень развития общественного питания. Отмечается направленность государственной политики на развитие торговли и службы быта, отраслей пищевой и легкой промышленности. Частичное внедрение новых мер сформировало противоречивую ситуацию в степени удовлетворения спроса населения при стабильном производственном росте на предприятиях края. Сделаны выводы о необходимости комплексного подхода к нововведениям с учетом предшествующего состояния экономики и региональных особенностей.

Ключевые слова: торговое обслуживание, экономические реформы, перестройка, рынок, история повседневности, Алтайский край.

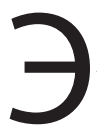
кономические реформы 1965 года и периода «перестройки» (1985-1991 гг.) оказали существенное влияние на уровень и качество повседневной жизни. Преобразования в отраслях тяжелой и легкой промышленности, торговом и бытовом обслуживании, организации общественного питания отразились на потребительских практиках и отношениях между основными экономическими акторами - производителем, продавцом и покупателем. Частичное внедрение новых мер в плановую систему хозяйствования и дальнейший переход отношений государства и предприятий к партнёрству сформировали противоречивую ситуацию в степени удовлетворения спроса населения при стабиль- ном производственном росте в регионе, совмещающем успешно функционирующие предприятия оборонной отрасли, легкой и пищевой промышленности и развитое сельское хозяйство.

Рассмотрим торговое обслуживание жителей региона в 1965-1991 гг. в контексте постепенной смены экономической модели - от традиционной для Советского Союза плановой системы хозяйствования к рыночной экономике в новой политической реальности. Восьмая «золотая» пятилетка (1966-1970 гг.) по общему объему продукции в Алтайском крае была выполнена досрочно. Объемы производства потребительских товаров воз- 
росли в 1,5 раза, среднегодовой прирост продукции в основном за счет повышения производительности труда составил более 8\%. Достижение плановых установок стало возможным благодаря внедрению новой техники и реконструкции промышленных предприятий. Во второй половине 1960-х гг. было установлено более 300 механизированных поточных и 30 автоматических линий, внедрено более 4 тыс. прогрессивных технологических процессов, модернизировано 8 тыс. единиц оборудования, построено 250 новых предприятий, 57 цехов и производств, более 2 тыс. животноводческих помещений, расширены мощности мясокомбинатов и молочных заводов $[22$, с. 73-74, 78].

Предприятия легкой промышленности к 1970 г. увеличили объем производства на 20\%. Выпуском промышленных товаров занимались 370 предприятий из 470 функционирующих на территории края [14, л. 7]. Хлопчатобумажных тканей в расчёте на душу населения производилось почти в 3 раза больше, чем в целом по РСФСР [22, С. 83]. В 1975 г. объем производства товаров широкого потребления увеличился на 40\%. Создано 144 образца новых машин и механизмов, освоено 729 видов продукции, 151 изделие выпускалось со Знаком качества $[15$, л. 24-26].

Алтайский край занимал ведущее место в стране не только по показателям легкой промышленности, но и по производству сельскохозяйственной продукции. В 1965-1970-е гг. производство сыра возросло на 42 \%, пива - на 28\%, безалкогольных напитков - на 73\%. Край являлся единственным в Сибири регионом по производству сахара и ведущим по производству мёда [19, с. 196]. По воспоминаниям жителей, Алтайские маслосыркомбинаты реализовывали разнообразные сорта сыра - кубанский, российский, советский, ярославский, костромской, степной, голландский [4, с. 4]. Помимо того, край обеспечивал в полной мере потребности населения региона и поставлял за его пределы сливочное и растительное масла, мясо, муку, колбасные, кондитерские и макаронные изделия [30, с. 174, 182]. В целом, производство пищевой продукции за 1965-1970 гг. возросло на $33 \%$, при увеличении численности работников на $10 \%$ и производительности труда на $16 \%$ [22, с. 83]. Объемы производства мяса, молока, яиц, зерновых круп, картофеля в среднем увеличились на $18,2 \%$, в девятой пятилетке (1971-1975 гг.) - на 12,4\% [19, с. 197]. Но в этот период сохранялась государственная направленность на развитие тяжелой промышленности. Производство продукции в машиностроении и металлообработке увеличилось на $72 \%$, химической промышленности - на 100 \%, нефтехимической отрасли - на 41 \% [22, с. 80-84].

К 1970 г. товары народного потребления производились на 170 предприятиях, объединенных шестью от- раслевыми хозрасчетными управлениями. В 1965-1970 гг. среднегодовой темп прироста в мебельном производстве составил 14,5 \%. Специализация мебельных фабрик позволила внедрить новые виды продукции: торговая, школьная, кухонная, мягкая мебель, гарнитурный набор «Жилая комната», шкафы для одежды, венские стулья [22, с. 81-84]. Современники также отмечали увеличение доступности и ассортимента товаров пищевой и промышленной отраслей [2, с. 3; 5, с. 4]. В связи со значительным увеличением производственных объемов наблюдался рост розничного товарооборота, включая общественное питание. За десятилетие к 1975 г. прирост составил 94\%, что несколько уступало динамике товарооборота по РСФСР (127,3\%) [20; 21]. Количество предприятий общепита Алтайского края с 1968 по 1971 гг. увеличилось в 1,5 раза, посадочных мест - в 1,3 раза [13, л. 35], что соответствовало общесоюзным темпам развития. Обеспеченность населения края сетью предприятий общепита в расчёте на 10 тыс. чел. (19 предприятий, 577 посадочных мест) превышала общесоюзный показатель (11 предприятий, 536 посадочных мест) [27, с. 17].

Следуя одной из мер экономической реформы по восстановлению системы отраслевого управления, в 1965 г. было создано Управление бытового обслуживания Алтайского края для руководства службой быта в регионе $[11$, л. 46]. В 1967 г. образовано Управление общественного питания Алтайского крайисполкома, в состав которого вошли тресты столовых и Алтайская краевая контора ресторанов и кафе [7, л. 57-68]. С целью улучшения оперативного руководства в 1975 г. создано Барнаульское хозрасчетное городское управление колхозными рынками [10, л. 24]. В его ведении находились Крытый рынок, Черёмушки, Октябрьский рынок, рынок ручной продажи, рынок пос. Восточный, Центральный рынок и рынок пос. Южный [11, л. 46].

В течение 1965-1970 гг. развитие получила широкая сеть многоотраслевых предприятий в городах и районах Алтайского края, деятельность которых была направлена на расширение бытовых услуг по ремонту и пошиву одежды и обуви, срочной стирке белья, выдаче напрокат предметов культурно-бытового назначения и крупной бытовой техники, парикмахерские услуги. Вводилась практика продажи в кредит цветных телевизоров, электрогитар, холодильников, магнитофонов, электропроигрывателей [9, л. 192-196]. Особое внимание уделялось воспитательной работе сотрудников службы быта, ориентации их на улучшение качества и культуры обслуживания. Однако потребитель отмечал продолжающиеся кадровые проблемы - низкий уровень квалификации мастеров, нахождение на рабочем месте в алкогольном опьянении и, как следствие, низкокачественный и длительный ремонт изделий [17, с. 3; 26, с. 3]. 
Строительство новых предприятий, создание системы объединений и комбинированных предприятий дали возможность увеличить предоставление бытовых услуг в 2,5 раза. В 1970 г. выпущено и реализовано 400 тыс. шт. одежды по фасонам и размерам заказчиков, более 150 тыс. пар кожаной обуви [22, с. 85]. Быстрый рост пользования сложной бытовой техникой привел в 1971 г. к увеличению объема услуг по её ремонту [23, с. 3]. В 1975 г. по сравнению с 1965 г. число предприятий бытового обслуживания увеличилось на 32,4 \%, что на 2,8 \% превышало показатель РСФСР. Объем выполненных работ в фактически отпускных ценах превысил показатель 1965 г. в 3 раза и показатель РСФСР 1975 г. - в 1,5 раза $[20 ; 21]$.

Повышение уровня жизни населения было невозможно исключительно на основе роста производительности предприятий и розничного товарооборота. Несомненно, требовалось улучшение качества реализуемых товаров и услуг. В торговлю внедрялся передовой метод самообслуживания, проводились открытые выставки товаров, продажа товаров по образцам, принимались заказы на пошив больших размеров швейных изделий и обуви по требованию покупателей [8, л. 503]. К 1970 г. предприятиями края было освоено свыше 360 новых видов промышленных изделий. В розничной продаже появились новые детские меховые пальто и пальто для детей дошкольного возраста, мужские спортивные куртки с подкладкой из меховых овчин, женские пальто из шубных овчин, более эффективные чистящие средства, художественные изделия из керамики и камня, масляная краска из местного сырья, хозяйственная посуда [22, с. 76].

Согласно новым экономическим мерам, заработная плата была поставлена в прямую зависимость от роста производительности труда. Это нововведение в полной мере соответствовало пониманию того, что образ жизни, прежде всего, находится в прямой зависимости от уровня доходов. Благодаря новой технике, технологии производства, организации труда предприятия стали получать сверхплановую прибыль, что позволило увеличить фонды развития и материального поощрения. В результате заработная плата одного работника промышленности в среднем возросла на 30\% - с 96 до 125,6 руб. Ежегодно наблюдалось увеличение премий из фонда материального поощрения. Если в 1966 г. удельный вес премий в фонде заработной платы составлял 0,1\%, то в 1970 г. - 5,7\% [22, с. 77]. Действительно рост доходов жителей края соответствовал предполагаемым результатам внедрения новых экономических мер. Но в итоге экономика столкнулась с новой проблемой: темпы промышленного производства не справлялись с растущими материальными потребностями населения, что привело к недостатку товаров повседневного спроса.
Подводя итоги экономическим преобразованиям середины 1960-х гг., можно отметить несомненные перемены в повседневной жизни населения Алтайского края. Перевод на отраслевой принцип руководства, переход органов управления на хозрасчет, новую систему планирования и экономического стимулирования создали условия для совершенствования производства. Наряду с ростом количественных показателей произошли качественные преобразования - укрупнение магазинов, увеличение количества предприятий общепита и посадочных мест, создание комбинатов бытового обслуживания. Результаты работы предприятий оценивались по увеличению реализованной продукции, росту прибыли и рентабельности производства. Такой подход требовал от производителя лучшего изучения потребностей населения. Но проблема ассортимента в связи с малоизученным спросом потребителя сохранялась. К концу 1980-х гг. сложились невысокий уровень социального развития и устойчивые диспропорции в экономике Алтайского края. К 1990 г. главной проблемой промышленности являлся износ производственных фондов. При этом уровень национального дохода на душу населения в крае был ниже, чем в других сибирских регионах - например, Новосибирской и Омской областях. Показатели прироста ВВП были ниже общероссийских [28, с. 34-38]. Из этого следует, что трансформация экономической системы была необходимым условием дальнейшего устойчивого развития региона.

Основным вопросом при подготовке экономического реформирования в годы «перестройки» стало расширение самостоятельности предприятий, перевод их на полный хозрасчет (самофинансирование, самоуправление, выбор коллективом руководителей) [32, с. 250-257]. Примером реализации этого условия может служить перевод 30 августа 1990 г. по решению трудового коллектива на арендную форму организации труда Центрального универмага, который получил основные фонды, инвентарь, оборотные средства и активы [29]. К 1992 г. в Алтайском крае функционировало 2910 приватизированных малых предприятий торговли и бытового обслуживания и 608 кооперативов, что превышало показатели других регионов Западно-Сибирского района $[24$, c. 79,84$]$.

Вводимые меры были призваны повысить ориентацию производства на потребителя, расширить свободу отдельных торгующих организаций в формировании ассортимента продукции и форм торгового облуживания. Но в условиях экономического спада предприятия испытывали финансовую трудность при покрытии вновь возникающих затрат на содержание объектов инфраструктуры, которые ранее относились к государственному балансу [18, с. 53-74]. 
Проведение реформы продолжилось реорганизацией органов государственного управления с целью сокращения бюрократического аппарата для более оперативного решения текущих задач на производстве и в сфере товарного обращения. Так, в 1991 г. было упразднено Управление торговли Алтайского крайисполкома [6, л. 250-252]. Реорганизовано Управление общественного питания в краевую фирму по оказанию услуг и координации хозяйственной деятельности предприятий общественного питания. В ведение вновь созданной организации были переданы тресты столовых Центрального, Октябрьского, Железнодорожного, Ленинского, Индустриального районов г. Барнаула, а также городов Бийска, Рубцовска, Славгорода и база материально-технического снабжения [12, л. 72, 77].

Однако реструктуризация привела к отрицательному результату. Ранее Управления владели комплексной информацией о региональных особенностях обслуживания и ситуацией в отдельно взятых торгующих организациях городов и районов краях. Непосредственное подчинение Минторгу РСФСР привело к усугублению неуправляемости предприятиями на местах. Территориальная удаленность от центра, отсутствие вертикали управления и, как следствие, бесконтрольность, привели к ухудшению торгового обслуживания и стали одной из причин усугубления товарного дефицита.

Низкая эффективность работы служб изучения спроса на товары в торговых организациях и на промышленных предприятиях привела к неравному соотношению спроса и предложения на товарный ассортимент. В 1986 г. к выпуску товаров для населения Алтайского края на 9 предприятиях было освоено свыше 900 видов изделий, обновлено более 200 моделей швейных и 62 трикотажных изделий. Вместе с тем готовая продукция «оседала» в магазинах и оптовых торговых предприятиях из-за низкого качества, несоответствия предлагаемого ассортимента потребностям населения. Кроме того, отмечалось низкая эффективность работы служб изучения спроса на товары и его прогнозирование в торговых организациях и на промышленных предприятиях [3, с. 3].

Проблема ассортимента дополнялась некомпетентностью торгового персонала. Показателен пример из обращения читателя в газету «Алтайская правда» 1986 года выпуска: «В наших магазинах есть морская рыба, креветки, кальмары. Мы - сибиряки, и далеко не каждый из нас знает, как их нужно готовить... Люди ходят с деньгами вокруг товаров и продуктов, а продавец, который обязан быть консультантом, не только молчит, но и на заданный вопрос, скорее всего, ответит "не знаю"» [16, с. 2]. Неудовлетворительным было санитарное состояние предприятий общественного питания в столовых Центрального и Железнодорожных районов г. Барнау- ла, наблюдались нарушения в хранении и технологии приготовлении блюд в ресторанах «Барнаул» и «Волна», общественным контролем отмечалась низкая культура обслуживания в продовольственных магазинах Индустриального, Центрального и Октябрьского района столицы региона [1, с. 2].

Рост покупательной способности населения и отсутствие нужного товара в легальной торговле привели к активному развитию деятельности теневой экономики и продаже по свободным ценам с активным применением техники блата. Продажа товаров наряду с официальной государственной розничной торговлей происходила и на полуофициальных «чёрных» рынках - «толкучках», «с рук», по выходным дням [9, л. 38-39, 288-309; 31, с. 5]. Еще одним недостатком при внедрении новой системы экономического планирования стали трудности в разработке механизмов по реализации региональных программ. Причиной являлась недостаточная информативная база вследствие необходимости решения беспрецедентных по сложности и новизне задач и отсутствия методических разработок в Госплане СССР, Министерстве экономике РСФСР и в Комитете по экономике администрации края [25, с. 44-45]. На государственном уровне не существовало целостной концепции реформ, что приводило к непоследовательности экономических преобразований в регионах.

Таким образом, торговое обслуживание в Алтайском крае находилось в прямой зависимости от общегосударственных экономических преобразований второй половины 1960-х и 1985-1991-х гг. Реформирование базировалось, прежде всего, на развитии торгового и бытового обслуживания, отраслей легкой и пищевой промышленности, укреплении материально-технической базы производства товаров народного потребления и упрочении системы службы быта. Прослеживается влияние проводимых реформ на изменения в развитии отдельных элементов региональной экономики - промышленности, торговли, службы быта, общественного питания.

Результатом перевода торгующих предприятий на полный хозрасчет и самофинансирование в период реформ правительства А.Н. Косыгина стали перемены в торговом секторе. Однако в системе управления торговлей во второй половине 1960-х - середине 1980-х гг. сохранялись так называемые «застойные» явления: отраслевой принцип управления народным хозяйством, нерациональность планирования, громоздкий управленческий аппарат, номенклатурное решение возникающих задач, отсутствие ориентации на потребности потребителя в сфере производства и товарного обеспечения. Обозначенные тенденции приводили к низкому качеству снабжения населения и дефициту отдельных видов товаров. Требовались радикальные изменения, 
способные в дальнейшем оказать позитивное влияние на функционирование торгующих организаций и качество торгового обслуживания. В последующий за этим период «перестройки» назрели сложные проблемы в социально-экономической и политической жизни. Вновь возникла необходимость проведения преобразований с целью изменений в сфере экономического развития и региональной торговли.

Общим для этапов проводимых реформ можно считать направленность государственной политики на развитие торгового обслуживания посредством перестройки способа хозяйствования отдельных предприятий, а не изменение экономической системы в целом. Переход к организационной самостоятельности требовал от руководителей знания экономики региона, логистики товаров, соответствующих навыков для выполнения планов товарооборота. В действительности управленче- ский аппарат торгующих организаций не был готов к решению обозначенных задач. Устоявшаяся плановая система не предполагала наличия предпринимательских способностей у руководства, что стало необходимым в новых экономических условиях. Как результат, основные усилия руководства и работников торговли были направлены в первую очередь на приспособление к деформированной системе. Вопросы же торгового обслуживания оставались второстепенными, что создавало социальную напряженность, усугубляло товарный дефицит и ухудшало качество обслуживания в розничной торговой сети, предприятиях общепита и организациях службы быта. Опыт трансформации торгового сектора под влиянием экономических реформ 1965 года и периода «перестройки» свидетельствует о необходимости комплексного подхода к нововведениям с учетом предшествующего состояния экономики и региональных особенностей.

\section{ЛИТЕРАТУРА}

1. Без холода и. . . от вчерашнего дня // Алтайская правда. 1990. 22 марта. № 68.

2. Больше местных товаров // Алтайская правда. 1966. 22 января. № 18.

3. В долгу у покупателя // Алтайская правда. 1987. 17 апреля. № 90.

4. В каком виде подавать сыр // Алтайская правда. 1966. 9 января. № 7.

5. В новом году - новая обувь // Алтайская правда. 1966. 9 января. № 7.

6. Государственный архив Алтайского края (далее - ГААК). Ф. Р-834. Оп. 4. Д. 226.

7. ГААК. Ф. Р-834. ОП. 6. Д. 814.

8. ГААК. Ф.Р-926. ОП. 2.Д. 14.

9. ГААК. Ф.Р-926. 0П. 3. Д. 78.

10. ГААК. Ф. Р-926. ОП. 4. Д. 187.

11. ГААК. Ф. Р-926. ОП. 4. Д. 206.

12. ГААК. Ф. Р-1573. 0п. 1.Д. 1.

13. ГААК. Ф. Р-1037. ОП. 4. Д. 12.

14. ГААК. Ф. Р-1033. ОП. 5. Д. 463.

15. ГААК. Ф. Р-1033. Оп. 5. Д. 464.

16. Давайте учиться торговать // Алтайская правда. 1986. 7 февраля. № 29.

17. Дорогой ремонт // Алтайская правда. 1966. 25 января. № 20.

18. Емельянова Т.П. Подходы и результаты исследования социально-экономического поведения приватизированных предприятий Алтайского края // С0циально-экономические последствия приватизации в проблемном регионе. Барнаул: Издательство Алтайского государственного университета, 1998. C. $53-74$.

19. История Алтая: в 3-Х т. Т. 3: Алтай в новейшую эпоху (XX - начало XXI века) / под ред. Е.В. Демчик. Барнаул: Издательство Алтайского университета; Белгород: Константа, 2019. 484 с.

20. Народное хозяйство РСФСР в 1965 г.: Стат. ежегодник. М.: Статистика, 1966. 616 c. URL: http://istmat.info/node/20469 (дата 0бращения: 19.11.2021).

21. Народное хозяйство РСФСР в 1975 г.: Стат. ежегодник. М.: Статистика, 1976. 519 с. URL: http://istmat.info/node/15622 (дата 0бращения: 19.11.2021).

22. Преображенный Алтай / под ред. А.И. Лизиной, Т.М. Макеева. Барнаул: Алтайское книжное издательство, 1967. 235 с.

23. Пятилетка. Год четвертый // Алтайская правда. 1970. 28 января. № 22.

24. Российская Федерация в 1992 году (Статистический ежегодник). М.: Республиканский информационно-издательский центр, 1993. URL: https://istmat.info/node/18226 (дата обращения: 20.11.2021).

25. Сибиркин Ф. Проблемы экономического планирования в переходный период к рыночной экономике // Экономическая реформа: оценка состояния экономики Алтайского края, ближайшие перспективы её развития: информационно - аналитический сборник. Барнаул: Администрация Алтайского края, 1994. С. 44-45.

26. Телевизор требует ремонта... (письма с комментариями) // Алтайская правда. 1966. 14 января. № 11.

27. Торговля СССР: Статистический сборник. М.: Финансы и статистика, 1989. URL: https://istmat.info/node/30999 (дата обращения: 20.11.2021). 
28. Троцковский А.Я. Региональная политика в агропромышленных регионах: (тартовое положение экономики края накануне реформ 1990-х гг. // 06разование и социальное развитие региона. 2001. № 1-2. С. 34-38.

29. Тюленева Т.Г. Центральный универмаг в Барнауле // Весь Алтай. URL: http://altlib.ru/territorii//barnaul/tsentralnyiy-univermag-v-barnaule/ (дата обращения: 14.11.2021).

30. Ужакин С.Ф., Ужакин А.С. Город на песках. Барнаул неформальный. Барнаул: [6. и.], 2013. 272 с.

31. «Чёрный» рынок: что почём // Алтайская правда. 1991. 2 ноября. № 218-219.

32. Шабашова Е.В. Деформация советской системы управления в период «перестройки» на примере государственной розничной торговли // Вестник МФЮА. 2017. № 1. С. 250-257.

(c) Демчик Евгения Валентиновна (demtchikev@mail.ru), Гряникова Галина Андреевна (galya9309@mail.ru).

Журнал «Современная наука: актуальные проблемы теории и практики»

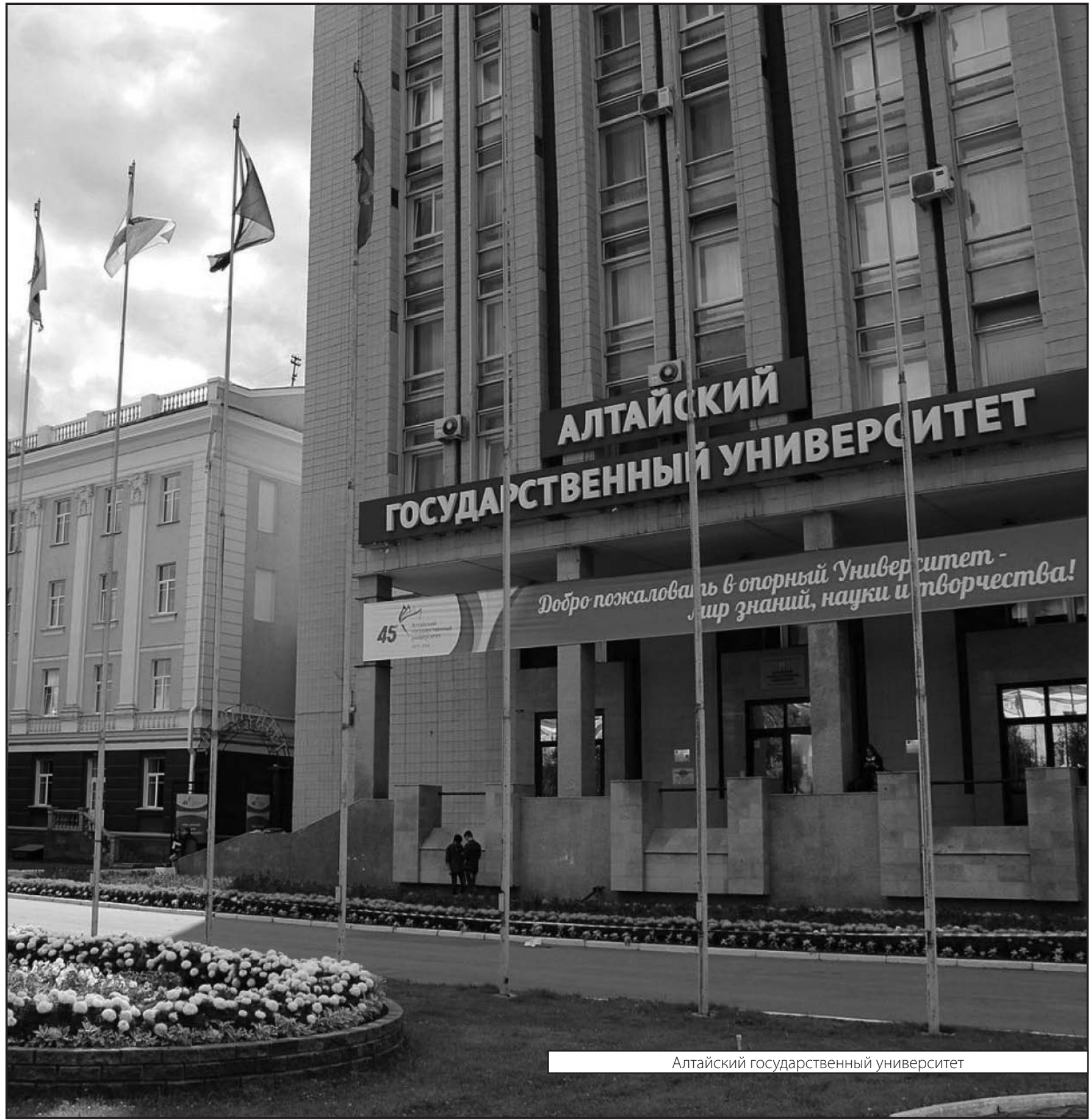

